Department of Anatomy and Histology,

Faculty of Veterinary Medicine, Assiut University.

\title{
EARLY EMBRYONIC DEVELOPMENT OF THE CAMEL LUMBAR SPINAL CORD SEGMENT.
}

\author{
(With 8 Figures)
}

\section{By \\ M.E. ABD ELMONEM; SALMA. A. MOHAMED* and K.H. ALY \\ *Department of Anatomy, Faculty of Veterinary Medicine, \\ South Valley University, Egypt. \\ (Received at 19/6/2005) \\ التطور الجنيني المبكر لقطعة الحبل الشوكي القطنية في الجمل \\ محهد المحرزى عبد المنعم ، سلمى أحمد محمد ، خالد حمدي على}

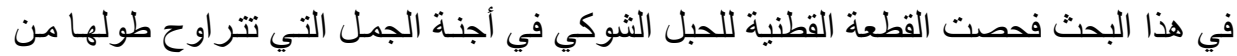

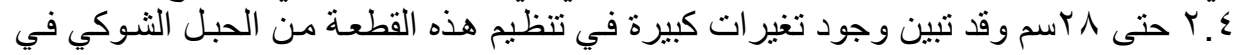

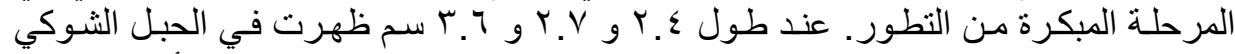

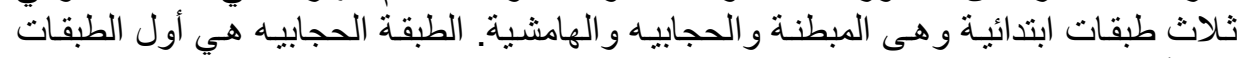

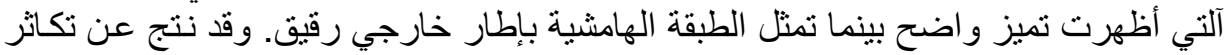

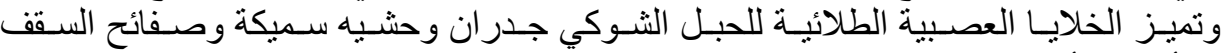

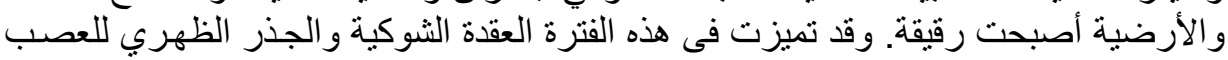

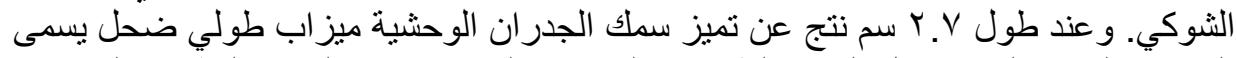

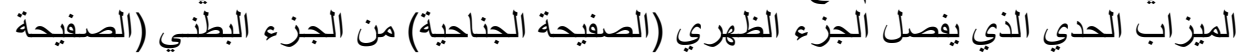

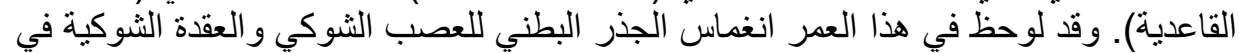

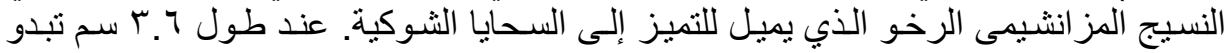

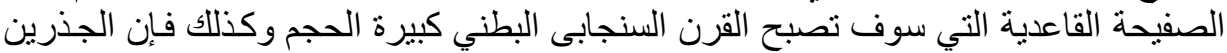

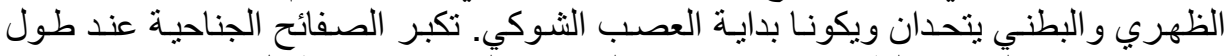

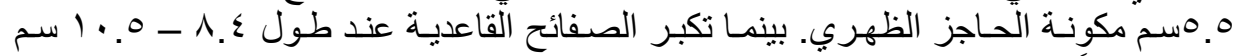

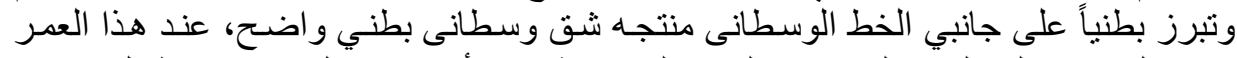

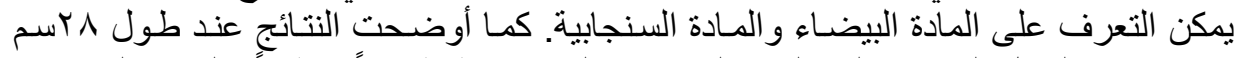

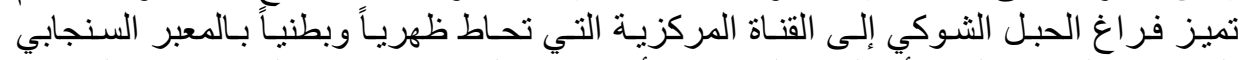

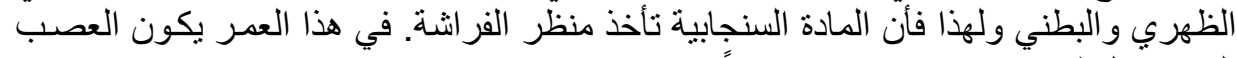

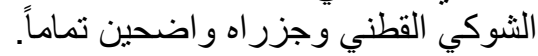

\section{SUMMARY}


The lumbar spinal cord segment of the camel embryos at 2.4 to $28 \mathrm{~cm}$ CVRL was examined. Major changes are occurring in the organization of the lumbar spinal cord segment at this early developmental period. At the 2.4, 2.7 and $3.6 \mathrm{~cm}$ CVRL the three primary layers; ependymal, mantle and marginal cells layer in the developing lumbar spinal cord segment were demonstrated. The mantle layer is the first to show striking differentiation while the marginal layer is represented by thin outer rim. Proliferation and differentiation of the neuroepithelial cells in the developing spinal cord produce the thick lateral walls, thin roof and floor plates. The spinal ganglion and dorsal root of the spinal nerve are differentiated. At $2.7 \mathrm{~cm}$ CVRL differential thickening of the lateral walls produces shallow longitudinal groove called sulcus limitans which separates the dorsal part (alar plate) from the ventral part (basal plate). The ventral root of the spinal nerve and the spinal cord ganglion are embedded in loose mesenchyme which tends to differentiate into spinal meninges. At $3.6 \mathrm{~cm} \mathrm{CVRL}$ the basal plate which is the future ventral gray horn is seen to be quite voluminous and the dorsal and ventral roots unite to form the beginning of the spinal nerve. At $5.5 \mathrm{~cm}$ CVRL the alar plates enlarge forming the dorsal septum. At 8.4 to $10.5 \mathrm{~cm}$ CVRL the basal plates enlarge, and bulge ventrally on each side of the midline producing the distinct ventral median fissure, the white and gray matters can be recognized. At $28 \mathrm{~cm}$ CVRL the lumen of the spinal cord is differentiated into the central canal bounded dorsally and ventrally by dorsal and ventral gray commissures therefore the gray matter takes the appearance of butterfly. The lumbar spinal nerve and their roots are well distinct.

Key words: Camel, spinal cord, development, Lumbar segment.

\section{INTRODUCTION}

The spinal cord is extremely important to overall function of the nervous system. It is the communication link between the brain and peripheral nervous system inferior to the head, integrating incoming information and producing responses through reflex mechanism (Seeley et al., 1992). There are important species differences at different stages of development of the central nervous system (Dyce et al., 1996). Although the development of the spinal cord was studied in some mammalian species (Arey, 1965; Balinsky, 1970; Macmillan, 1972; Freeman and Bracegirdle 1978; Valdes-Dapena, 1979; Nodeen and Lahunta, 1985 and Drews, 1995) information about the camel are 
meagre. The knowledge of the development of the different regions of the spinal cord is very important. It can explain the causes of some congenital anomalies; also, it helps in identification of cellular differentiation of some tumours. Therefore, the aim of the present work is to give full data about the early development of the lumbar spinal cord segment in camel.

\section{MATERIALS and METHODS}

The present study was carried out on 24 embryos of one humped camel (Camelus dromedaries), collected from Cairo slaughter house. The CVR length of these embryos were 2.4, 2.7, 3.6, 3.9, 5.5, 8.4, 10.5 and $28 \mathrm{~cm}$ (three of each age were used). After slaughtering the mothers, the embryos were collected and immersed in $10 \%$ formalin. The specimens dehydrated in graded alcohol series, cleared in methyle benzoate, embedded in paraffin. The specimens were cut of serially in the lumbar region of the body. The prepared sections were stained with Haematoxylin and eosin for general histological structures.

\section{RESULTS}

At the 2.4 to $2.7 \mathrm{~cm}$ CVRL (Figs. 1,2) the lumbar spinal cord segment is characterized by the presence of wide spindle-shaped lumen which represents the cavity of the immediately closed neural tube. This lumen extends nearly along the whole height of the spinal cord, its dorsal end is wider than ventral end. The dorsoventral diameter of the lumbar spinal cord segment, in cross section, is larger than its mediolateral diameter. Consequently the spinal cord appears flattened from side to side, it is also noted that the ventral region of spinal cord is wider than the dorsal region.

At this developmental period the spinal cord is formed of six plates; roof, floor, two alar and two basal plates. The dorsal and ventral midline portions of the immediately closed neural tube known as the roof and floor respectively. The dorsal part (alar plate) and the ventral part (basal plate) are separated from each other by sulcus limitans at 2.7 cm CVRL.

The lumbar spinal cord segment at this period consists of three concentric layers; an inner ependymal, middle mantle and outer marginal layer. The roof plate consists of ependymal layer only, while the floor plate consists of marginal layer in addition to previous layer. However the alar and basal plates are formed of three layers. The neuroepithelial 
cells of the ependymal layer line the lumen of the spinal cord. This layer of the roof plate is narrower than the other regions of the spinal cord. The mantle layer is the thickest of the three layers, it is absent at the roof and floor plates, but it is thicker at the basal plate than at the alar plate. The marginal layer is represented by a thin outer rim encloses the mantle layer except at the floor plate where it encloses the ependymal layer. The marginal layer increases in thickness from the dorsal to the ventral direction.

The dorsal spinal ganglion, at the 2.4 to $2.7 \mathrm{~cm} \mathrm{CVRL}$, appears as an elongated mass flattened from side to side and is separated from the basal plate, by a large space filling by mesenchymal cells. At $2.4 \mathrm{~cm}$ CVRL the dorsal root of the primitive spinal nerve was observed connecting the lateral aspect of the alar plate with the dorsal spinal ganglion. On the other hand, the ventral root of the primitive spinal nerve appears later at $2.7 \mathrm{~cm} \mathrm{CVRL}$, it leaves the ventrolateral aspect of the basal plate. The spinal cord, the dorsal spinal ganglion, the dorsal and ventral roots of the primitive spinal nerve are embedded in loose mesenchymal tissue which tends to differentiate into the future spinal meninges.

At 3.6 to $3.9 \mathrm{~cm}$ CVRL (Figs. 3,4) the lumen of the spinal cord begins to reduce, therefore it occupies about three fourths the total height of the spinal cord. The basal plate which is the future ventral gray horn is seen to be quite voluminous, inturn the spinal cord increases in the transverse direction. As a result in this stage the dorsoventral diameter of the spinal cord becomes nearly equal to its mediolateral diameter. At $3.6 \mathrm{~cm}$ CVRL the ventral region of the spinal cord is wider than the dorsal region, but at $3.9 \mathrm{~cm}$ CVRL the both previous regions become nearly equal.

The mantle layer appears at the roof and floor plates, but it is thicker at the former plate than at the other one. This layer is thicker at the alar plate than the basal plate. The marginal layer is demonstrated at the roof plate. It increases in thickness especially in the ventral direction and it is more thicker than the previous stage. The dorsal and ventral roots unite to form the initial part of the spinal nerve. The dorsal spinal ganglion becomes larger and separated from the spinal cord by a narrow area of mesenchymal tissue. At $3.9 \mathrm{~cm}$ CVRL the spinal meninges can be differentiated around the marginal layer of the spinal cord.

At $5.5 \mathrm{~cm}$ CVRL (Fig. 5) the lumen of the spinal cord changes in shape and size, it becomes diamond in shape and occupies about half of the total height of the spinal cord. The dorsoventeral diameter of the 
spinal cord becomes smaller than the mediolateral diameter. Consequently the spinal cord appears flattened dorsoventrally. The marginal layers of the right and left alar plates enlarge and converge together forming with the roof plate the dorsal median septum and the dorsal median sulcus. On the contrary, the marginal layer of the right and left basal plates enlarge and diverge from each other forming future ventral median fissure which is filled with the cells of the mantle layer and pia matter, therefore this fissure has the septum like appearance. The dorsal median septum and the ventral median fissure extend ventrally and dorsally till connecting the lumen of the spinal cord. The mantle layer becomes voluminous laterally at both the alar and basal plates. The marginal layer becomes thicker than the previous stage. It is thickest laterally and dorsally and thinnest ventrally.

At 8.4 to $10.5 \mathrm{~cm}$ CVRL (Figs. 6,7) the lumen of the spinal cord is greatly reduced occupying about one fourth of the total height of the spinal cord. The mantle layer begins to differentiate into the innermost gray matter, and the marginal layer into the outermost white matter. At this period the basal plates become larger and bulge ventrally on each side of the midline producing distinct ventral median fissure. Due to the reduction in the size of the lumen of the spinal cord the ventral median fissure lost its connection with the spinal lumen leaving an area known as white commissure through which the marginal layers of both right and left basal plates (white matter) communicate. The three layers of the spinal meninges can be recognized at $10.5 \mathrm{~cm}$ CVRL.

At $28 \mathrm{~cm}$ CVRL (Fig.8) the spinal cord tends to attain the mature form. The lumen of the spinal cord is seen to be greatly obliterated, therefore it differentiates into distinct small narrow oval central canal which occupies only about one seventh of the total height of the spinal cord. Mylinization of the marginal layers takes place forming the white matter which can be differentiated into dorsal, lateral and ventral funiculi. The proportion of the white matter increases more than the previous stage. The gray matter differentiates into dorsal and ventral horns, its right and left sides communicate with each other above and below the central canal through the dorsal and ventral gray commissures, therefore the gray matter takes the appearance of butterfly. At this stage, the dorsal horn tends to have greater volume than the ventral horn. The lumbar spinal nerve, their roots and the dorsal spinal ganglion are well distinct. 


\section{DISCUSSION}

According to the recent study a pronounced changes were observed in the shape and size of the lumen of the lumbar spinal cord segment during the early developmental period. The lumen of the spinal cord is wide spindle in shape at $2.4 \mathrm{~cm}$ CVRL, diamond in shape at 5.5 $\mathrm{cm}$ CVRL and narrow oval in shape at $28 \mathrm{~cm}$ CVRL.

It occupies about the whole, half and one seventh of the total height of the spinal cord at 2.4, 5.5 and $28 \mathrm{~cm}$ CVRL respectively. In this respect, Kaufman (1992) stated that in mouse at 11.5-12 days pregnancy the shape of the central canal is fairly similar throughout the entire length of the cord with the dorsal half being considerably more voluminous than the ventral half. Between 12.5-13 and 15.5 days pregnancy the volume of the central canal gradually diminishes. But by about 16.5-17.5 days pregnancy the lumen of the central canal is seen to be almost obliterated. Brookes and Zietman (1998) reported that in the $4^{\text {th }}$ week of development the neural tube has an oval neural canal, in the $5^{\text {th }}$ week the canal becomes diamond-shaped and a bilateral sulcus limitans separates an alar and basal laminae, in the $6^{\text {th }}$ week, the sulcus limitans is lost and neural canal is key-hole shaped. The changes in the shape and size of the lumen of the spinal cord may be in relationship to the decrease of the ependymal layer and the increase of the mantle layer during developmental stages. Patten (1953) supported this opinion and indicated that during the growth of the manle layer, the originally extensive lumen of the neural tube is reduced to the small ventral canal characteristic of adult cord. By far the greater part of this reduction is reflected by the obliteration of what was the dorsal portion of the original lumen. The cells of the ependymal layer now constitute a short of epithelial lining of the central canal.

The present study emphasizes the presence of considerable difference between both dorsoventral and mediolateral diameters of lumbar spinal cord segment with increased gestational age. The dorsoventral diameter is larger than the mediolateral diameter at 2.4 to $2.7 \mathrm{~cm}$ CVRL, then the former diameter becomes smaller than the latter diameter at 3.6 to $5.5 \mathrm{~cm}$ CVRL. The two diameters are nearly equal at $8.4 \mathrm{~cm}$ CVRL, after that the dorsoventral diameter becomes larger than the mediolateral diameter. The relationship between the two diameters reflects the various shapes of the cross section of the spinal cord at different stages. 
The present work shows that at 2.4 to $2.7 \mathrm{~cm} \mathrm{CVRL}$, the spinal cord is formed of six plates; roof, floor, two alar and two basal plates. Sadler (1990) explained that as a result of continuous addition of the neuroblasts to the mantle layer, each side of the neural tube shows a ventral and a dorsal thickenings. The ventral thickenings; the basal plates, contain ventral motor horn cells and form the motor area of the spinal cord; the dorsal thickenings; alar plate, form the sensory area of the spinal cord. The dorsal and ventral midline portions of the neural tube , roof and floor plates, respectively, don't contain neuroblasts and serve primarily as pathway for nerve fibers crossing from one side to other. Dyce et al. (1996) confirmed this result and stated that the alar plate is the location of the afferent neurons, while the basal plate is the location of the efferent neurons.

The present investigation indicates that the distribution of the ependymal, mantle and marginal layers differ in the various developmental stages of the camel embryos. It is concluded that the majority of the cross section of the spinal cord consists at first of ependymal and mantle layers, and there is only a thin outer rim of the marginal layer. With advancement of the age the ependymal layer diminishes in size, while the mantle and marginal layers increase in size forming the future gray and white matters respectively. In this connection Sadler (1990) and Dyce et al. (1996) reported in the human embryos that the neuroepithelial layer after the closure of the neural tube begins to give the neuroblasts which form the mantle layer. The nerve fibers emerging from the neuroblasts within the mantle layer extend outward and form marginal layer.

Corresponding to the present work, the marginal layer at 2.4 to $2.7 \mathrm{~cm}$ CVRL camel embryos is represented by a thin outer rim enclosing the mantle layer. With the advancement of the age this layer increases extensively in mass and producing the white matter as recorded in human embryos by Patten (1953). This author attributed the growth of this layer to the secondary addition, outside the gray matter, of longitudinally disposed neuron processes which constitute the conduction paths between the various levels of the spinal cord and the brain. When later in development, such fiber tracts become mylinated, they import to the proportions of the cord in which they lie a characteristic whitish appearance contrasting strongly with the gray colour of richly cellular portion of cord derived from the mantle layer. Evans (1993) agreed that the concentrated myelin lipids is responsible for the pale appearance of the unstained white matter. According to Fix 
(1996), April (1997) and Rakhawy (2000) the bundles of nerve axons of the white matter are organized into numerous descending (sensory) and ascending (motor) tracts, some of which cross in the white commissure to the contralateral side. In $7^{\text {th }}$ and $8^{\text {th }}$ week the marginal zone of the cord is transformed into neurofibrous white matter by developing nerve tracts (Brookes and Zietman, 1998).

The dorsal root of the primitive spinal nerve appears in the examined camel embryos at $2.4 \mathrm{~cm}$ CVRL connecting the lateral aspect of the alar plate with the dorsal spinal ganglion. On the other hand, the ventral root appears at $2.7 \mathrm{~cm}$ CVRL leaving the ventrolateral aspect of the basal plate. At these ages the dorsal spinal ganglion appears as an elongated mass flattened from side to side. At 3.6 to $3.9 \mathrm{~cm}$ CVRL the two roots unit to form the primitive spinal nerve. At $28 \mathrm{~cm}$ CVRL the lumbar spinal nerve and their roots as well as the dorsal spinal ganglion become well distinct. Patten (1953) explained that the processes growing out from developing neurons lying in the ventrolateral portions of the mantle layer of the cord establish the ventral roots of the spinal nerves. Neuroblasts in the dorsal root ganglion send to the cord afferent processes which collectively constitute the dorsal roots of the spinal nerves. Seeley et al. (1992) indicated that the dorsal roots possess, the dorsal root ganglia which contain the cell bodies of the sensory neurons.

At $5.5 \mathrm{~cm}$ CVRL camel embryos, the alar plates enlarge and converge forming the dorsal median septum, and the basal plate enlarge and diverge forming the future ventral median fissure which is filled with the cell of mantle layer and pia matter.

At 8.4 to $10.5 \mathrm{~cm}$ CVRL the basal plate become larger and bulge ventrally producing distinct ventral median fissure. This statement is conformed by Dyce et al. (1996) who reported that further growth of the alar and basal plates causes the lateral parts of the tube wall to expand outward in all directions, submerging the roof and floor plates and creating the dorsal sulcus and the ventral fissure that divide the adult cord into its right and left halves.

\section{LEGENDS}


Fig. 1: Paraffin section showing the lumbar spinal cord segment at 2.4 cm CVRL stained with H\&E X ( 250).

Fig. 2: Paraffin section showing the lumbar spinal cord segment at 2.7 cm CVRL stained with H\&E X (100).

Fig. 3: Paraffin section showing the lumbar spinal cord segment at 3.6 cm CVRL stained with H\&E X (100).

Fig. 4: Paraffin section showing the lumbar spinal cord segment at 3.9 cm CVRL stained with H\&E X (100).

Fig. 5: Paraffin section showing the lumbar spinal cord segment at 5.5 cm CVRL stained with H\&E X (100).

Fig. 6: Paraffin section showing the lumbar spinal cord segment at 8.4 cm CVRL stained with H\&E X (100).

Fig. 7: Paraffin section showing the lumbar spinal cord segment at 10.5 cm CVRL stained with H\&E X (40).

Fig. 8: Paraffin section showing the lumbar spinal cord segment at 28 cm CVRL stained with H\&E X (40).

1- Ependymal layer

2- Mantle layer

3- Marginal layer

4- Dorsal spinal ganglion

5- Roof plate

6- Floor plate

7- Alar plate
8- Basal plate

9- Sulcus limitans

10- Dorsal root

11- Ventral root

12- Spinal nerve

13- Dorsal median septum

14- Ventral median fissure

15- Dorsal gray horn

16- Ventral gray horn

17- Central canal

18- Dorsal gray commissure

19- Ventral gray commissure

20- White matter

\section{REFERENCES}

April, E.W. (1997): Clinical Anatomy. $3^{\text {rd }}$ Edition. Williams \& Wilkins. Arey, L.B. (1965): Developmental Anatomy, A textbook and laboratory manual of embryology. $7^{\text {th }}$ Edition. W.B. Saunders Company, Philadelphia, London, 529-541.

Balinsky, B.I. (1970): An Introduction to Embryology. $3^{\text {rd }}$ Edition. W. B. Saunders Company, Philadelphia, London.

Brookes, M. and Zeitman, A.C. (1998): Clinical Embyology. A colour Atlas and Text. CRC Press. 
Deyer, W. (1998): Neuroanatomy. $2^{\text {nd }}$ Edition. Williams \& Wilkins.

Drews, U. (1995): Color atlas of embryology. Georg Theime Verlag Stuttgart. New York, Thieme Medical publishers, Inc. New York.

Dyce. K.; Sack, W.O. and Wensing, C.J.G. (1996): Textbook of Veterinary Anatomy $2^{\text {nd }}$ Edition. W. B. Saunders company. A division of Harcourt Brace Jouanovichinc. Philadelphia, London, Toronto, Montreal, Sydney, Tokyo.

Evans, H.E. (1993): Miller's Anatomy of the dog. $3^{\text {rd }}$ Edition W. B. Saunders Company A division of Harcourth Brace \& Company. Philadelphia, London, Toronto, Montreal, Sydney, Tokyo.

Fix, J.D. (1996): Brood Review Series; Neuroanatomy. $2^{\text {nd }}$ Edition. Williams\& Wilkins.

Freeman, W.H. and Bracegirdle B. (1978): An Atlas of Embryology. $3^{\text {rd }}$ Edition. Heinemann Educational Books, London.

Kaufman, M.H. (1992): The atlas of Mouse development. Academic Press. Haecourt Brace Jovanovich, Publishers. London, San Diego, New York, Boston, Sydney, Tokyo and Toronto.

Macmillan, W.W. (1972): Atlas of descriptive Embryology. $2^{\text {nd }}$ Edition. Macmillan Publishing co., Inc. New York. Collier Macmillian Publishers, London.

Nodeen, D.M. and Lahunta, A. (1985): The Embryology of Domestic Animals. Developmental Mechanisms and Malformations. Williams \& Wilkins, Baltimore, London.

Patten, B.M. (1953): Human Embryology. $2^{\text {nd }}$ Edition. McGRAW-HILL Book Company. New York, Toronto and London

Rakhawy, M.T. (2000): Neuroanatomy for medical students. Department of Anatomy, Faculty of Medicine, Cairo University.

Sadler, T.W. (1990): Langman's Medical Embryology. $6^{\text {th }}$ Edition. Williams \& Wilkins.

Seeley, R.R.; Stephens, T.O. and Tate, P. (1992): Anatomy and Physiology. $2^{\text {nd }}$ Edition. Mosby year Book.

Valdes,-Dapena, M.A. (1979): Histology of the foetus and newborn. W. B. Saunders Company Philadelphia, London, Toronto. 